\title{
Rooftop Air-Conditioning Unit Performance Improvement using Refrigerant Circuitry Optimization
}

\author{
Yashar, D.A. ${ }^{1 *}$, Lee, $^{2}{ }^{2}$, and Domanski, P.A. ${ }^{1}$ \\ ${ }^{1}$ Energy and Environment Division, National Institute of Standards and Technology, Gaithersburg, MD 20899, USA \\ ${ }^{2}$ Research Reactor System Design Division, Korea Atomic Energy Research Institute, Yuseong-gu, Daejeon, 305-353, Korea \\ *Corresponding author email address: dyashar@nist.gov
}

\begin{abstract}
This study demonstrates the performance improvement of an air-to-air 7.5 Ton $(26.4 \mathrm{~kW})$ rooftop unit (RTU) achieved by optimizing an evaporator's refrigerant circuitry using evolutionary algorithms. We measured its cooling capacity and Coefficient of Performance (COP) in an environmental chamber where we also measured the in-situ air velocity profile using Particle Image Velocimetry (PIV).

We used a detailed heat exchanger model to simulate the performance of the original evaporator operating with the measured air distribution, and then we used an evolutionary algorithm-based optimization module embedded in the simulation tool to optimize the refrigerant circuitry for the measured inlet air distribution.

The optimized refrigerant circuitry design was implemented in a new prototype evaporator, which replaced the original evaporator in the tested RTU system. Laboratory tests of the new system showed an improvement of $2.2 \pm 1.5 \%$ in capacity and $2.9 \pm 1.5 \%$ in COP compared to the performance of the original system, which was optimized by the manufacturer using conventional methods prior to the onset of this study.
\end{abstract}

Keywords: Air Velocity Profile, Roof Top Air Conditioning Unit, Particle Image Velocimetry (PIV), Circuitry optimization 


\section{INTRODUCTION}

Finned-tube heat exchangers are the predominant type of heat exchangers used in comfort cooling applications. They consist of a bundle of several dozen connected tubes and the performance of the heat exchanger as a whole is the aggregate performance of every tube in the bundle. The heat transfer performance of each individual tube is influenced by many parameters including the tube and fin geometries; the refrigerant temperature, mass flux and local quality; and the local air velocity, temperature and humidity. The local air velocity is one of the most important parameters because it dictates the amount of air that is available for heat exchange and influences the local air-side heat transfer coefficient. To this end, the distribution of the air incident on the heat exchanger has a profound impact on its overall performance, since it characterizes the velocity of air at each tube location in the bundle.

There has been long standing interest in airflow distributions through finned-tube heat exchangers. The first documented study was that of Fagan (1980), which examined small heat exchangers used in room air conditioners. His study showed that typical units often have quite large velocity variations and that the impact on performance is significant. Chwalowski et al. (1989) later showed similar results and went on to demonstrate as much as a $30 \%$ variation in capacity for a given evaporator when subject to different airflow distributions. Payne et al. (2003) demonstrated that airflow nonuniformity can impose a significant reduction in heat exchanger capacity, as much as $30 \%$ in the extreme cases, which agrees with the earlier work by Chwalowski et al. More recently, Kaern (2011a, 2011b) conducted a numerical study of air maldistribution in finned-tube evaporators for a nominal $8.8 \mathrm{~kW}$ residential air-conditioning system and showed that the coefficient of performance (COP) decreased as much as $43 \%$ for the worst case of non-uniform airflow.

Along the way, several researchers began to shift their focus away from trying to achieve uniform airflow so that the heat exchangers work well to designing heat exchangers that will perform well with the expected nonuniform airflow. In order to consider this option, one must first be able to determine the in-situ airflow distribution with a high degree of confidence. For this reason, Yashar et al. (2011, 2014) used PIV and CFD to measure and model, respectively, the distribution of air passing through finned-tube heat exchangers. 
The other part of designing a highly efficient heat exchanger is to route the refrigerant in such a way that it most effectively exchanges heat with the air. Recently, some sophisticated approaches have been developed that employ genetic algorithm (GA) based optimization methods to design the optimal refrigerant circuitry for the actual airflow distribution seen by the heat exchangers. One tool that uses this method is the Intelligent System for Heat Exchanger Design (ISHED) (Domanski and Yashar, 2010). Several studies from this group have demonstrated that designing the optimal refrigerant circuitry for the actual airflow distribution can result in significant improvements in capacity and COP while simultaneously reducing the size, cost, and amount refrigerant charge. Wu et al. (2008a, 2008b) built a similar type of GA module based on a heat exchanger simulation model by Liu et al. (2004). Their optimization module was used to determine refrigerant circuitries that minimized the material cost and maximized the heat transfer capacity. The objective of the present study is to experimentally demonstrate the system performance improvement achieved by optimizing the evaporator's refrigerant circuitry for the in-situ air velocity distribution.

\section{EXPERIMENTAL SETUP}

\section{Rooftop Air-Conditioning Unit}

The system examined in this study is a small commercial 7.5 Ton $(26.4 \mathrm{~kW})$ air-to-air, R410A Rooftop Unit (RTU). It has two separate refrigerant loops for operation under part load or full load conditions. Each stage has its own compressor, condenser and expansion valve. The unit has a single evaporator slab that is shared by the two stages with each stage utilizing half of the available heat transfer area. A cutaway schematic of the unit is shown in Figure 1. The unit is sectioned into three compartments; the middle evaporator compartment is the focus of this study; it is where the air is conditioned and blown into the discharge compartment and ultimately into the building. 


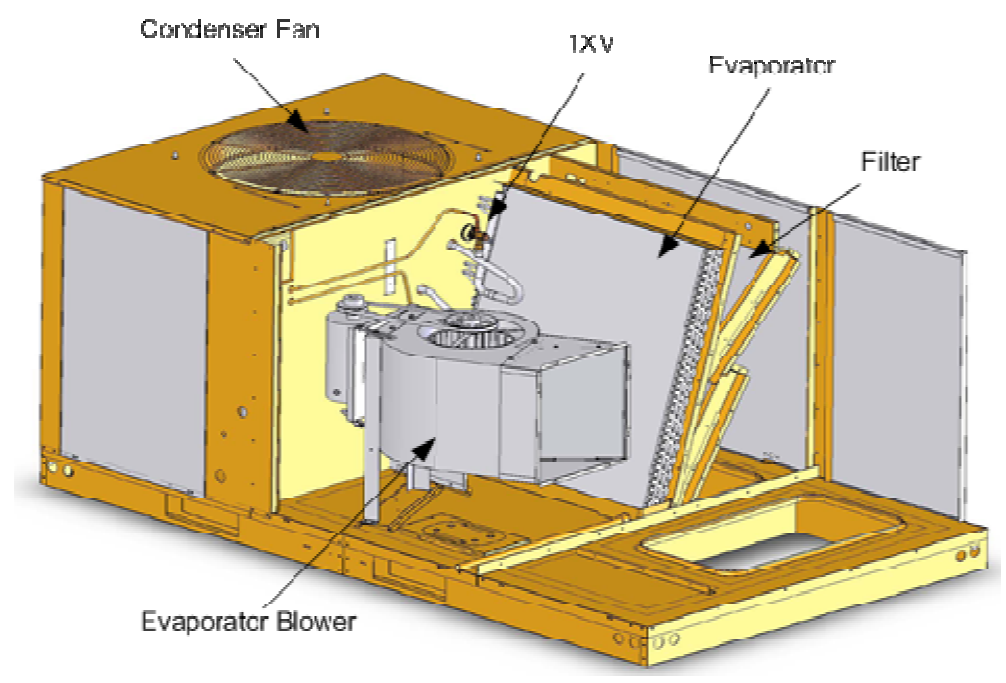

Figure 1 Schematic of Test Subject

Figure 2 shows a side view of the middle compartment. The building air enters this compartment through an intake port (not shown) located at the bottom right in the figure, then passes through a set of air filters and the evaporator. After the evaporator, the air enters a blower which circulates it through the unit.

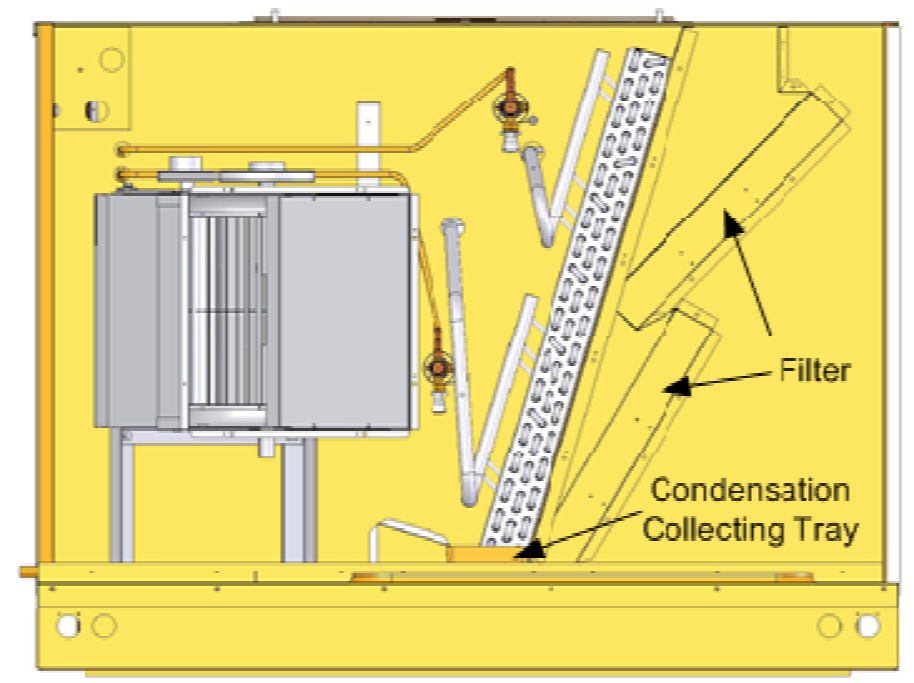

Figure 2 Middle Compartment of Test Subject

The evaporator slab is made up of 144 tubes located in four depth rows with louvered fins. The tubes have an outside diameter of $9.52 \mathrm{~mm}$ and are spaced $25.4 \mathrm{~mm}$ apart along the height of the heat exchanger. The depth rows were layered in a staggered configuration and are spaced $22 \mathrm{~mm}$ apart. The overall dimensions of the evaporator are $914 \mathrm{~mm}$ tall, $864 \mathrm{~mm}$ wide, and $101.6 \mathrm{~mm}$ thick. The total heat transfer area provided by the 
evaporator is divided amongst the two stages of the system. In total the evaporator has 16 refrigerant circuits with 8 circuits used by each stage; each circuit consists of either 8 or 10 tubes.

\section{Instrumentation}

Figure 3 shows a schematic of the test apparatus with the position of the points along the two refrigerant loops where the refrigerant temperature and pressure were measured (A, $\mathrm{B}$, and $\mathrm{C}$ ). The stage 1 loop is described by the refrigerant vapor exiting the stage 1 compressor at point $1 \mathrm{~A}$, and then condensed into a liquid in the stage 1 condenser. The liquid refrigerant exiting the stage 1 condenser flows through a coriolis mass flow meter and then onto point 1B, just before entering the enclosure for the RTU. Once inside, it is flashed by passing through the stage 1 TXV. After expansion, the refrigerant is distributed amongst 8 different circuits in the evaporator, which exit the evaporator through a header tube at point $1 \mathrm{C}$, and then continue out of the enclosure and back to the stage 1 compressor. The stage 2 loop is schematically identical to the stage 1 loop, and the measurement positions are likewise labeled $2 \mathrm{~A}-2 \mathrm{C}$. The condensers used in this test setup were water-cooled brazed-plate heat exchangers, instead of the original finned-tube air-to-refrigerant condensers, because this study focused on the evaporator and this allowed testing the unit with a single environmental chamber.

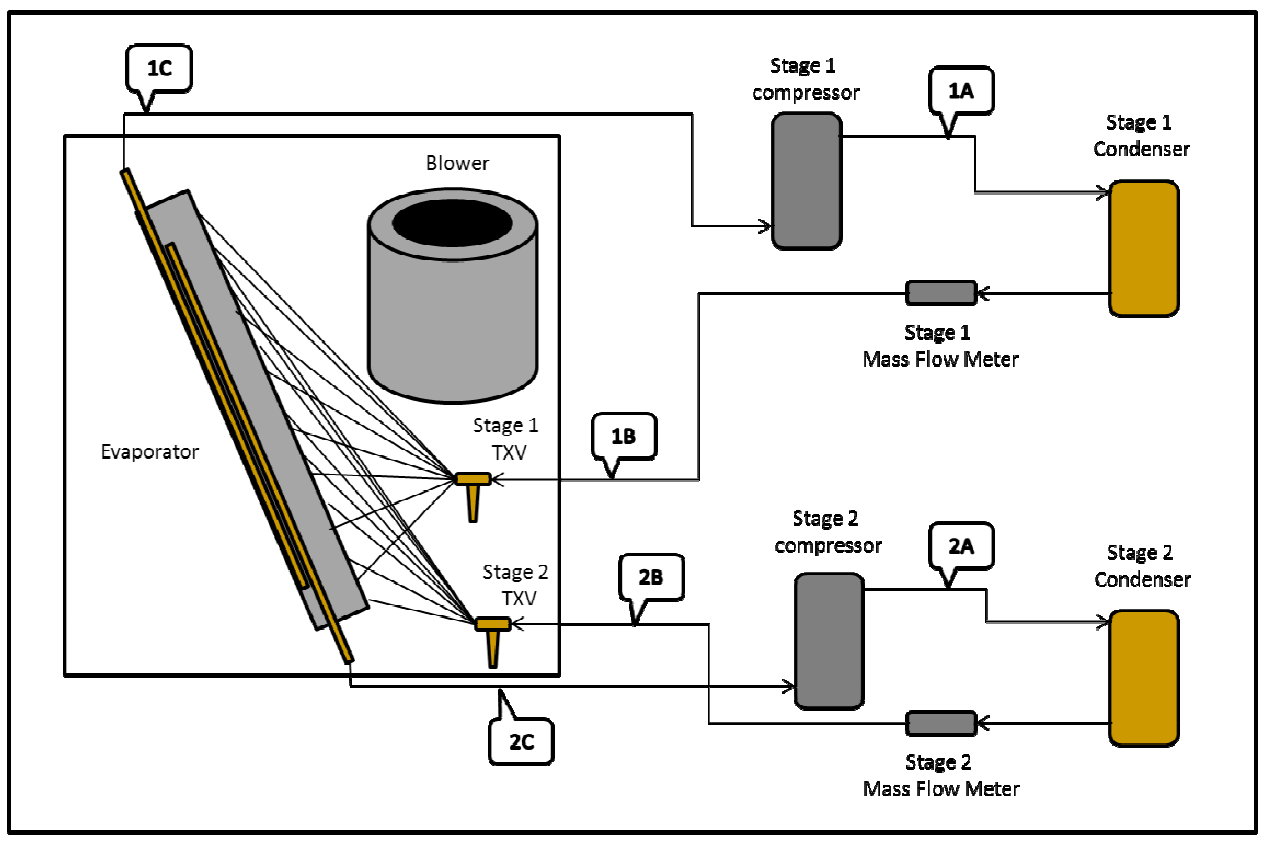

Figure 3 Refrigerant Flow Loops (Stage 1 and Stage 2) 
The refrigerant pressure was measured using pressure transducers with a 0 to $3447 \mathrm{kPa}$ range and uncertainty of $\pm 0.13 \%$ full scale at $95 \%$ confidence. The refrigerant temperature was measured using T-type thermocouples probes immersed in the flow, calibrated to $0.15 \mathrm{~K}$ at $95 \%$ confidence. We also measured the refrigerant temperature at several of the heat exchanger return bends using thermocouples adhered to the outside of the select tubes. The refrigerant mass flow rate for each refrigerant loop was measured using coriolis mass flow meters calibrated to $\pm 1 \%$ at $95 \%$ confidence. Using these instruments, the cooling capacity of the heat exchanger could be readily calculated using the difference between the refrigerant liquid line and vapor line enthalpies and the refrigerant mass flow rate. The electrical power input to the blower and each compressor was measured using three separate power analyzers calibrated to $\pm 0.25 \%$ at $95 \%$ confidence. Using these instruments, the uncertainty associated with the cooling capacity and COP was always lower than $1.1 \%$; a full analysis of the uncertainty is described in Yashar and Lee (2013).

\section{SYSTEM TESTS WITH ORIGINAL EVAPORATOR}

\section{Performance Tests}

A series of tests were performed to characterize the performance of the unit operating with the original evaporator in a large environmental chamber that has a capacity of $35 \mathrm{~kW}(120000 \mathrm{Btu} / \mathrm{h})$ and dry-bulb and $\mathrm{RH}$ control better than $\pm 1{ }^{\circ} \mathrm{C}\left(2^{\circ} \mathrm{F}\right)$ and $\pm 2 \%$, respectively. The unit was tested with the air conditions specified in AHRI Standard $340 / 360$ (2007), $26.7^{\circ} \mathrm{C}\left(80^{\circ} \mathrm{F}\right)$ dry bulb and $19.4^{\circ} \mathrm{C}\left(67^{\circ} \mathrm{F}\right)$ wet bulb delivered to the unit at a rate of $1.42 \mathrm{~m}^{3} \mathrm{~s}^{-1}(3000 \mathrm{CFM})$. The air temperature and humidity were monitored at the intake to the unit as shown in Figure 4, and the air leaving the unit was ducted through a flow measurement section to measure the exit conditions and flow rate. 


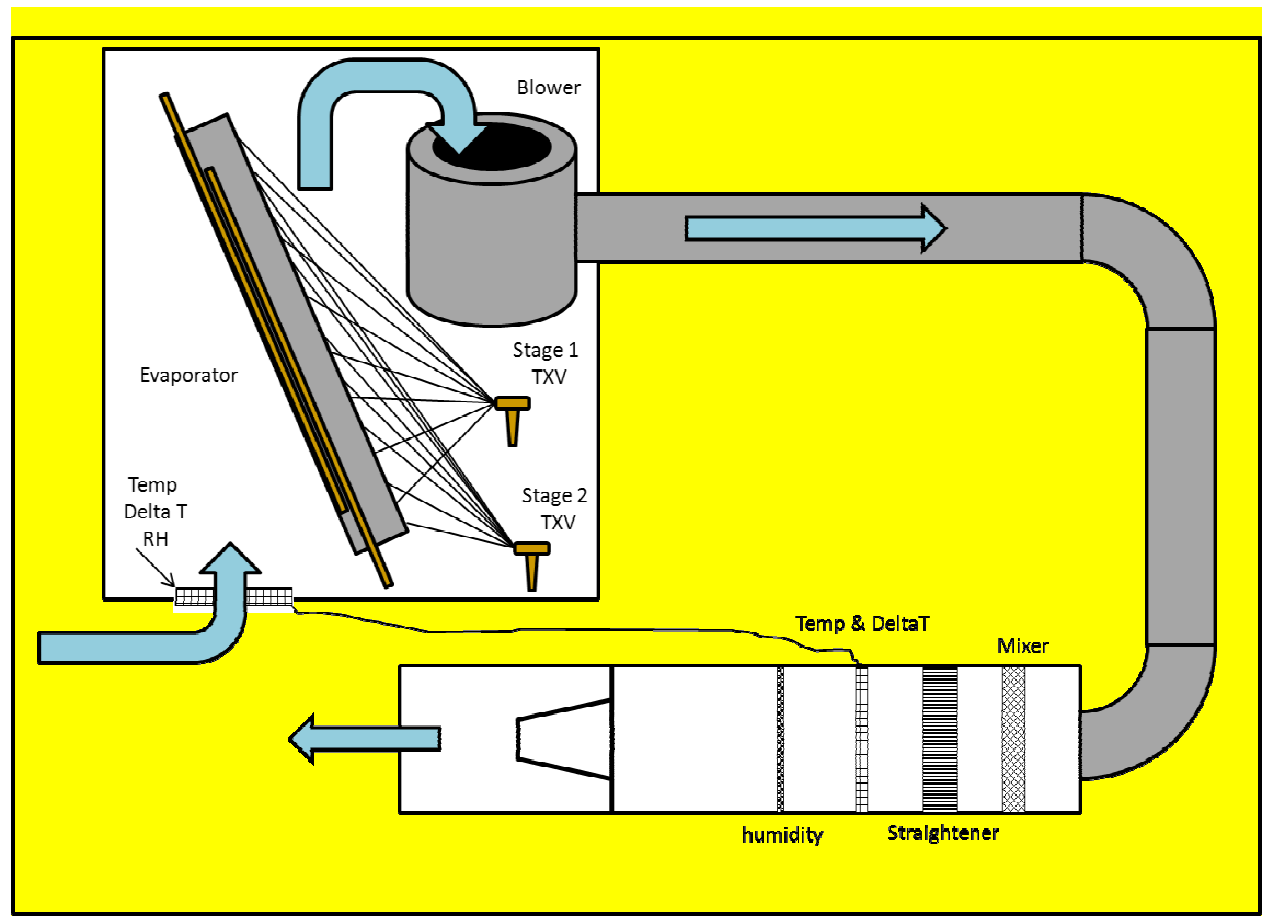

Figure 4 Air Flow Measurement and Control

The RTU manufacturer assisted with this project by providing their test data for this unit, and that data served as a basis for the RTU setup and operation during this study. Since the original air-to-refrigerant condensers were replaced with water-cooled, brazed-plate heat exchangers, the unit was charged with refrigerant such that the liquid line temperature and pressure matched the manufacturer's test data, which allowed the RTU's evaporator portion to operate as it would in a typical installation.

During our tests the capacity measured by the air enthalpy method was typically $2 \%-3 \%$ lower than the capacity measured by the refrigerant enthalpy. The main contribution for this difference is conduction of heat through the enclosure walls. This effect was significant because insulation was removed from the RTU's enclosure in order to outfit it with the acrylic panels and provide visual access inside during operation. The air infiltration into the negative pressure compartment of the enclosure was another significant factor to this difference. For this reason it was determined that the refrigerant side capacity measurements would provide a better basis for this work than the air-side capacity measurements, which are required by the standard test method, since it is a direct measurement of the evaporator's performance.

A total of eight individual measurements of the system's capacity were recorded over a 
two week period. The average capacity measured during these tests was (26.42 $\pm 0.29) \mathrm{kW}$, which is within $1.8 \%$ of the value from the manufacturer's certification data of $26.85 \mathrm{~kW}$. A more detailed description of the experiments discussed here can be found in Yashar and Lee (2013).

\section{Airflow Distribution Measurements}

The airflow distribution at the evaporator inlet was measured while operating the unit under performance test conditions. We chose to use PIV to collect the air velocity data; however CFD or other models could provide this information at a much lower cost, once suitable models are available. In order to ensure that the heat exchanger was operating in a steady manner with an adequate level of condensate on the outside surface, the unit was operated continuously for a minimum of 30 minutes before collecting each set of airflow distribution data. Air velocity data was collected at six different lateral positions along the surface of the heat exchanger. The positions that were queried are indicated in Figure 5. 


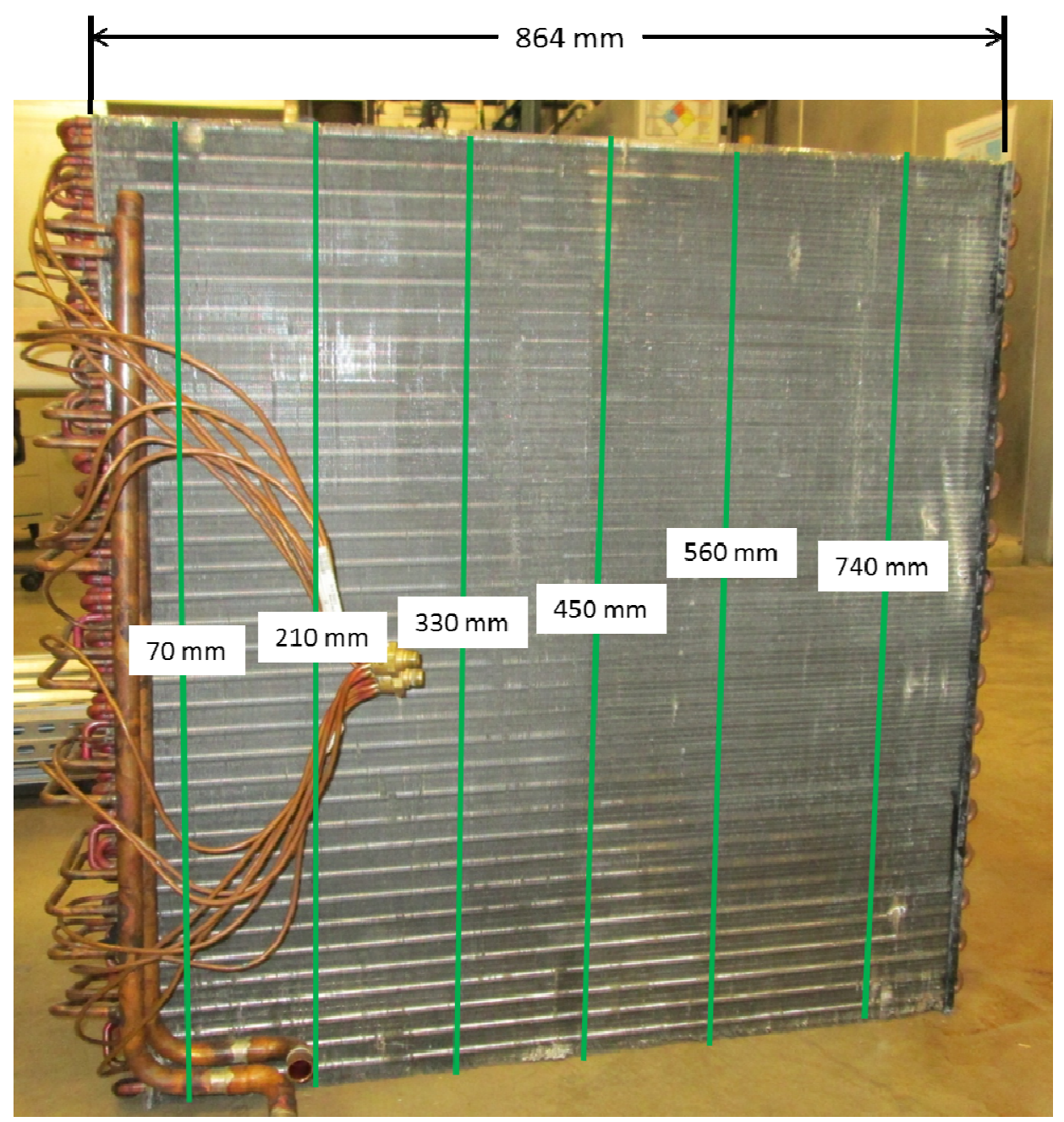

Figure 5 Evaporator with Marked Air Velocity Measurement Planes

The velocity distribution data sets were compiled for each of the 6 lateral positions, and it was assembled into the flow map shown in Figure 6. This figure was constructed by linearly interpolating between the data collected at each of the adjacent data sets. This flow map shows several patterns that are a result of the features within the RTU enclosure; for example, the airflow near the bottom of the heat exchanger (vertical distance > $800 \mathrm{~mm}$ ) is significantly impeded by the condensate collection pan located there and it is also impeded near the lateral midline of the map by the mounting bracket for the unit's air filter located upstream of the heat exchanger. Overall, the measurements showed that the air velocities passing through the heat exchanger during normal operation varied by a factor of $6\left(0.5 \mathrm{~ms}^{-1}\right.$ to $\left.3.0 \mathrm{~ms}^{-1}\right)$ depending on location. 


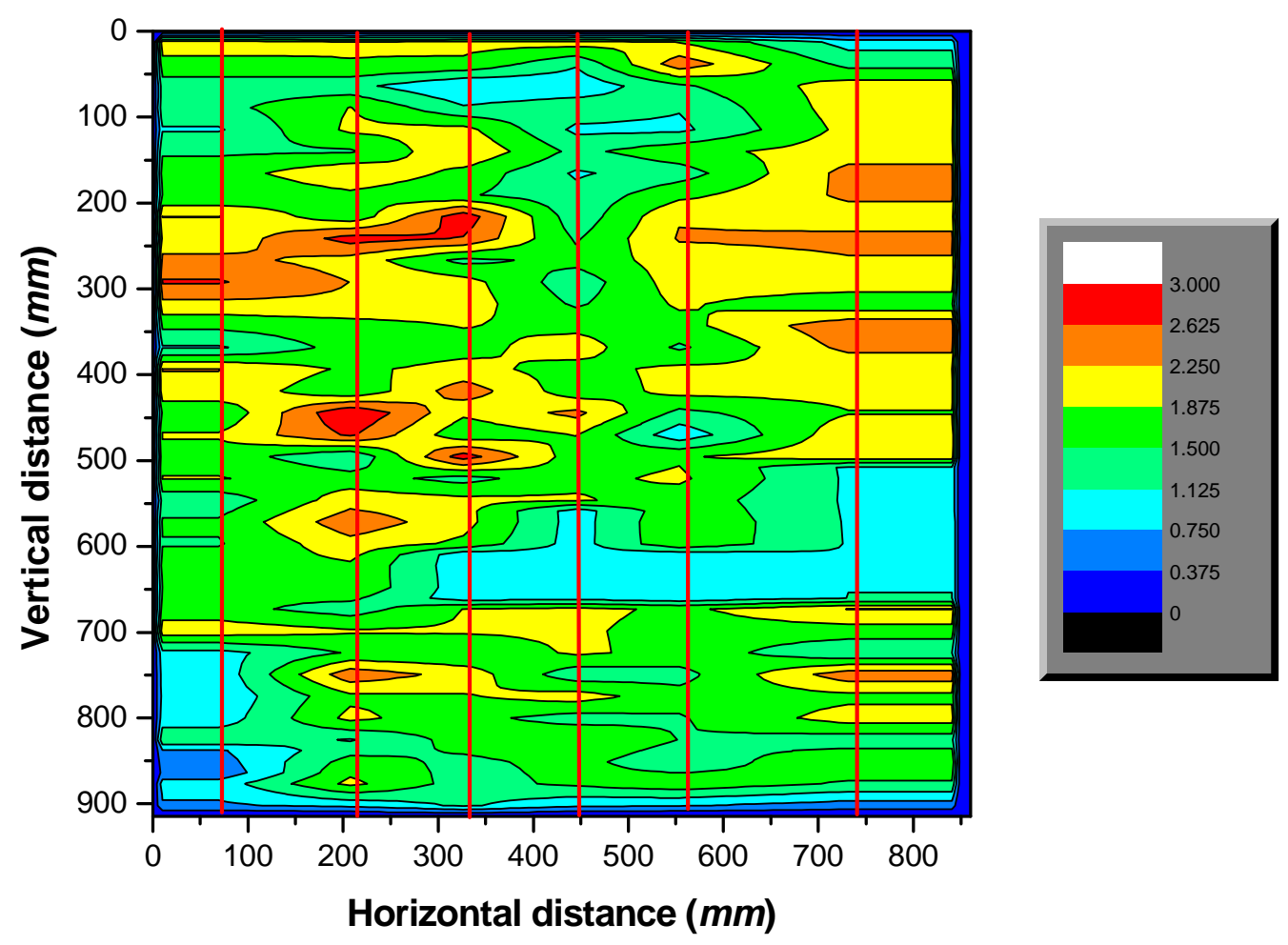

Figure 6 Air Velocity Flow Map

Once the flow map was complete, data was extracted from it to approximate the air distribution with a one-dimensional velocity profile required as input for the heat exchanger simulation model used in this study. This was done by integrating the magnitude of velocity in the horizontal direction. The velocity map was numerically integrated resulting in the pattern shown in Figure 7. It is realized that an analysis based on the 2-D velocity profile could provide some additional performance improvement beyond a 1-D analysis; however, this was the limit of the simulation tool available at the time of this study. 


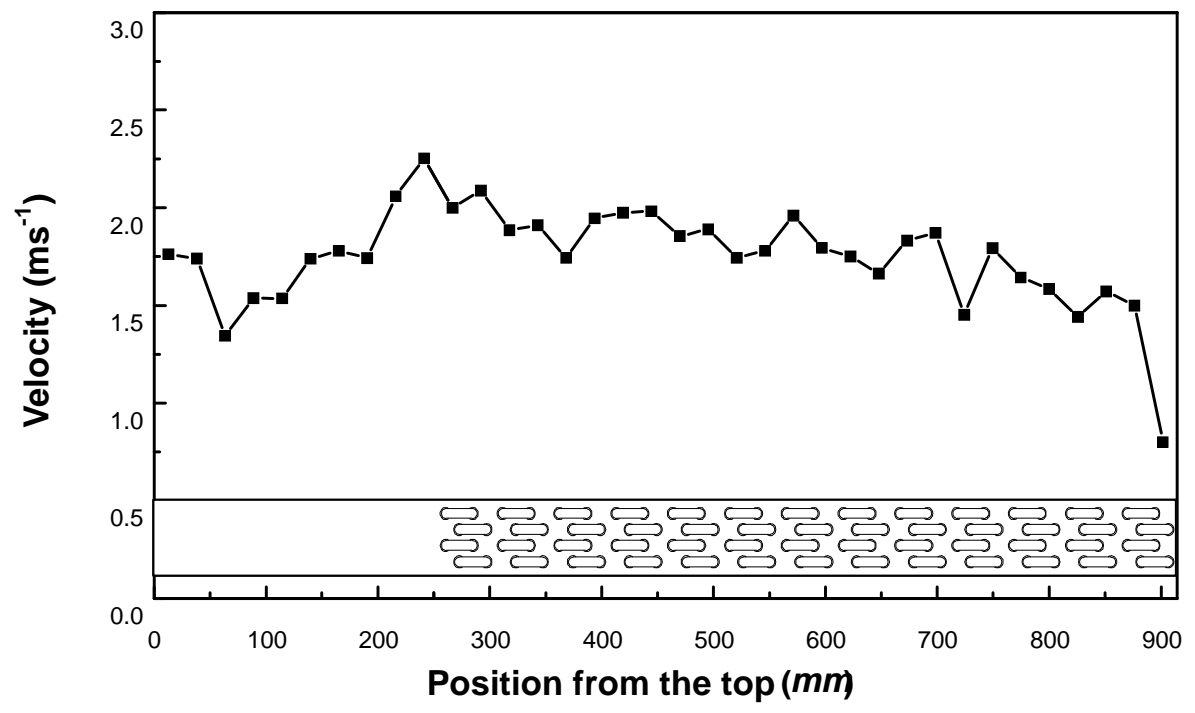

Figure 7 1-D Flow Distribution

\section{EVAPORATOR CIRCUITRY OPTIMIZATION}

\section{Modeling and Simulating Performance of the Original Evaporator}

The computational portion of this study was performed using the EVAP-COND package (Domanski and Yashar, 2010), a public domain software package developed by the National Institute of Standards and Technology (NIST). The program is a firstprinciples based simulation tool that calculates the performance of finned-tube, air-torefrigerant heat exchangers on a tube-by-tube basis. The first step of this phase was to prepare a model of the evaporator with this software, including the original refrigerant circuitry, as shown below in Figure 8. In this figure, the refrigerant inlet tubes are shown as thick-walled red circles, and the refrigerant exit tubes are shown as thick-walled blue circles. The return bends are shown as lines connecting the tubes; the solid lines represent return bends on the near side of the heat exchanger, and the dashed lines represent return bends on the far side.

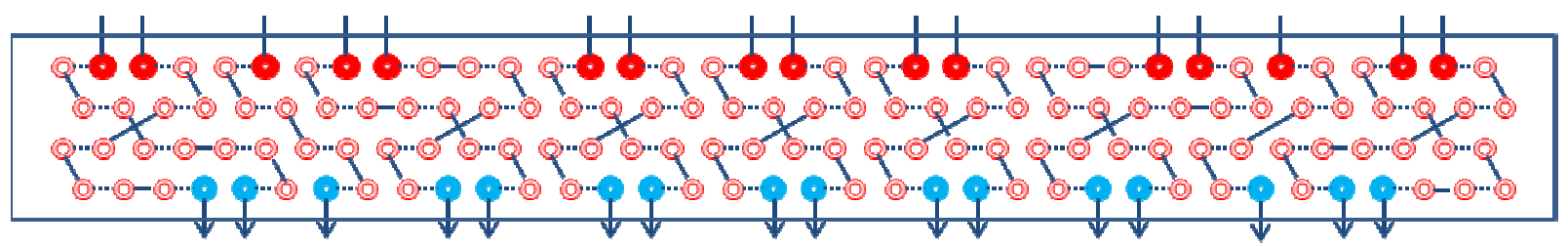

Figure 8 Schematic Side View of Original Evaporator Circuitry Design 
After preparing the model, the operating conditions as measured during the laboratory tests were input to the simulation model along with the 1-D airflow distribution shown in Figure 7. The model was tuned to exactly match the laboratory measurements using by adjusting the correction factor multipliers for the refrigerant heat transfer coefficient, refrigerant pressure drop, and air-side heat transfer coefficient.

The original evaporator design consists of 16 circuits, and each circuit is comprised of either 8 or 10 tubes to preserve the hairpin pattern. It is obvious that the 10 -tube circuits would impart more pressure drop on the refrigerant flowing through them than the 8 -tube circuits, if all other factors were equal. However, since the pressure drop through each circuit must be equal, the 8-tube circuits will generally receive a higher mass flow rate of refrigerant than the 10-tube circuits. It is important to know that the distribution of the airflow also affects the refrigerant distribution because it influences the heat transfer rate on the local level. As the refrigerant absorbs heat it changes phase from liquid to vapor and accelerates due to the change in density; the resulting higher velocity also increases the frictional pressure drop.

All of the 10-tube circuits of the original evaporator had superheated refrigerant at their exit because the length of these circuits would cause refrigerant to be preferentially routed through the 8 -tube circuits and because they have $25 \%$ more heat transfer area than the 8-tube circuits. Three of the 8-tube circuits also resulted in a refrigerant exit condition of superheated vapor while the other five did not. The 8-tube circuits that resulted in a superheated exit condition were concentrated in locations that received more airflow than the other 8-tube circuits.

\section{Optimization Runs}

Once the heat exchanger model was tuned to the test results, it was used for optimizing the refrigerant circuitry using the Intelligent System for Heat Exchanger (ISHED) module. ISHED is an evolutionary algorithm-based optimization module (Yashar et al. 2012) that maximizes the heat exchanger capacity by searching for the optimal refrigerant circuitry. While the optimization method is quite complex, ISHED is bundled with Versions 3.0 and higher of EVAP-COND and is therefore free for public use. Based on the principles of evolution, ISHED operates on one set or 'generation' of refrigerant circuitries at a time, and forms subsequent solution generations based on the simulation results. Table 1 shows the parameters used as input to control each optimization run, as guided by Domanski et 
al. (2011).

Table 1 ISHED Control Parameters for Circuitry Optimization Run

\begin{tabular}{|l|l|}
\hline Number of designs per generation & 40 \\
\hline Number of generations & 250 \\
\hline Minimum number of inlet tubes & 12 \\
\hline Maximum number of inlet tubes & 18 \\
\hline
\end{tabular}

The evaporator optimization runs were performed with conditions of imposed inlet quality of $22.4 \%$ and refrigerant saturation temperature of $11.7^{\circ} \mathrm{C}$ and superheat of $4 \mathrm{~K}$ at the evaporator exit, which were obtained from the performance data with the original evaporator. The immediate measure of evaporator improvement due to optimized refrigerant circuitry is the increase of evaporator capacity over that of the original evaporator capacity at this particular operating regime. The increase in capacity is associated with the same increase in refrigerant mass flow rate since the specific change of enthalpy in the evaporator is constant during optimization runs. It should be noted that the improvement of capacity of the actual system is expected to be somewhat smaller than that obtained from evaporator simulations because the compressor will not be able to provide an increase in refrigerant mass flow rate; this results in an increase evaporator saturation temperature and some improvement of the system COP.

In total, seven optimization runs were performed and the best performing design from those runs was selected for further examination. The best optimized design contained several complex return bend configurations which would be extremely difficult or impossible to manufacture. For this reason it was manually altered to clean up the circuitry while preserving the characteristics of the optimized design, a process described in Domanski et al. (2011).

Figure 9 shows the final optimized design, which achieved a capacity $7.9 \%$ higher than the original design. This design includes 2 more refrigerant circuits than the original design (18 vs. 16), with each of the circuits using 8 tubes and providing a similar amount of heat transfer and pressure drop. Because of the way that this design balances the pressure drop and the mass flow rate per circuit, it will impart a smaller pressure drop onto the refrigerant than the original design at the same total mass flow rate. 


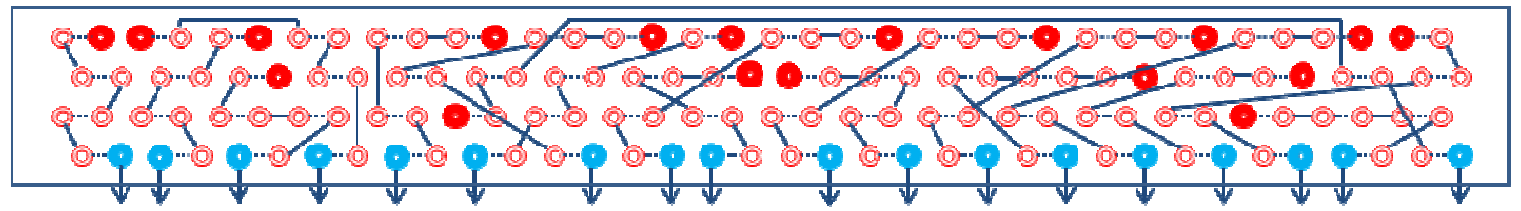

Figure 9 Schematic Side View of ISHED Optimized Refrigerant Circuitry Design

\section{SYSTEM TESTS WITH OPTIMIZED EVAPORATOR}

\section{System Setup and Test Results}

The RTU manufacturer built a prototype of the evaporator with the optimized circuitry.

Figure 10 shows side views of both the original and optimized evaporators.

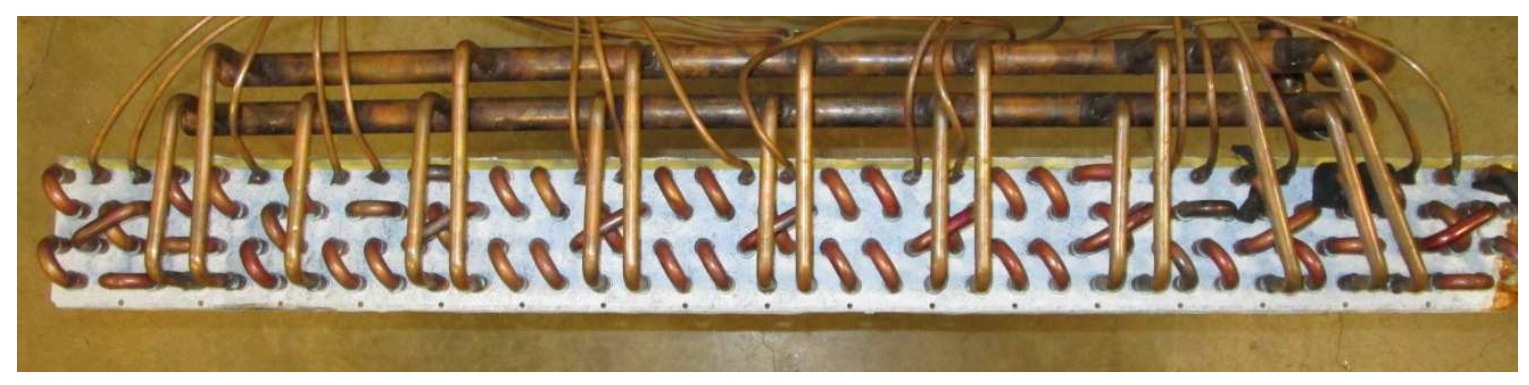

(a)

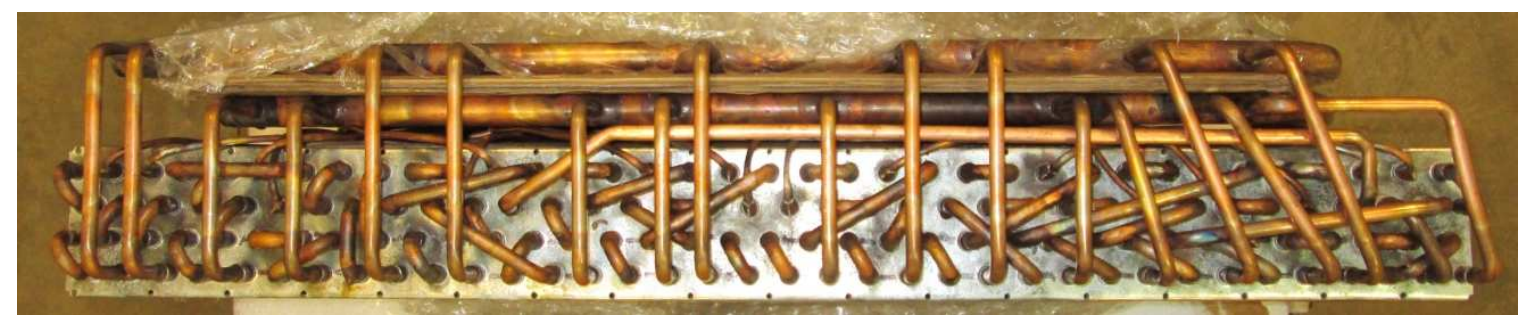

(b)

Figure 10 Prototypes of (a) Original Evaporator and (b) Optimized Evaporator

The optimized evaporator was installed in the RTU, and nine independent measurements of the system performance were acquired over a two week period. The average value from these nine tests shows a total capacity of $(27.01 \pm 0.25) \mathrm{kW}$ and a system COP of $3.88 \pm 0.04$.

\section{Discussion of Measured Performance Improvement}

The system capacity with the optimized evaporator was $2.2 \pm 1.5 \%$ greater than the 
capacity with the original evaporator. The upper limit of the $95 \%$ confidence interval for the system capacity with the original evaporator is marginally lower than the lower limit of the $95 \%$ confidence interval for the system capacity with the optimized evaporator. However, it should be noted that the $2.2 \%$ capacity increase is in line with the improvement prediction by the analytical method in Domanski (1988), which estimates a $2.9 \%$ system capacity increase if the evaporator capacity were increased by $7.9 \%$. The COP of the system with the optimized evaporator is $3.88 \pm 0.04$, which represents $2.9 \pm 1.5 \%$ increase in efficiency over the system with the original evaporator.

Considering that the measured capacity and COP improvements are relatively small and are burdened with measurement uncertainty, it is prudent to examine other measurements that may corroborate the measured improved performance. In this respect, the most important single measurements is the evaporator exit saturation temperature, which was significantly higher in each stage during the tests with the optimized evaporator than with the original evaporator. The exit saturation temperature for Stage 1 was $(11.5 \pm 0.1)^{\circ} \mathrm{C}$ under the test conditions with the original evaporator, and the optimized evaporator circuitry raised it to $(12.4 \pm 0.1)^{\circ} \mathrm{C}$; an increase of $(0.9 \pm 0.1) \mathrm{K}$. Similarly, the exit saturation temperature for Stage 2 was raised from $(11.4 \pm 0.1)^{\circ} \mathrm{C}$ to $(12.1 \pm 0.1){ }^{\circ} \mathrm{C}$ with the optimized evaporator, an increase of $(0.7 \pm 0.1) \mathrm{K}$. This increase in evaporating temperature realized in each stage is quite significant compared to the limits of the $95 \%$ confidence intervals and indicates a real benefit resulting from the optimized circuitry.

This increase in evaporation temperature comes from two aspects of the optimized design. First, this design provides a better match between the air and refrigerant temperature profiles; therefore, the overall temperature difference between the air and refrigerant is reduced. Since the inlet air temperature is constant, the smaller temperature difference results in an increased R410A saturation temperature inside the evaporator. Second, since the optimized evaporator consists of the same amount of heat transfer area as the original evaporator, but uses 18 circuits instead of 16, the refrigerant mass flux (and therefore pressure drop) will be lower. This results in a smaller drop in saturation temperature as the refrigerant passes through the heat exchanger.

\section{CONCLUSIONS}

This study demonstrates the benefits of optimizing the refrigerant circuitry on an air-torefrigerant finned-tube evaporator in a 7.5 Ton R410A RTU. The RTU used in this 
study was a commercial unit, which included an evaporator that the manufacturer had designed and optimized using conventional methods. The measured improvement of performance was a $2.2 \%$ capacity and $2.9 \%$ COP increase over the manufacturer's original optimized design.

The concept illustrated in this study depends on measurements of evaporator air distribution for input to the refrigerant circuitry optimization module. Detailed measurements using PIV constituted a substantial experimental effort; therefore the practicality of the presented concept relies on the ability of determining accurate representations of the air velocity profile using simpler methods. For this reason further research efforts should focus on development methods and tools for determining air velocity profiles for typical installation configurations and on improving CFD tools for application in these configurations.

\section{ACKNOWLEDGEMENTS}

This study was sponsored by the United States Department of Energy, Building Technologies Office under B\&R Code BT0302000-05450-1004215-Sp Cond \& Ref R\&D with project managers Antonio Bouza and Bahman Habibzadeh. In kind support was provided by the Nordyne Corporation.

\section{REFERENCES}

ARI 2007. Standard 340/360-2007, Performance Rating of Commercial and Industrial Unitary Air-Conditioning and Heat Pump Equipment. Air-Conditioning ,Heating, and Refrigeration Institute, Arlington, VA.

Chwalowski, M., Didion, D. A., Domanski, P. A., 1989. Verification of Evaporator Computer Models and Analysis of Performance of an Evaporator Coil. ASHRAE Transactions 95(1): 793-802.

Domanski, P.A., 1988. Rating of Mixed Split Residential Air Conditioners.

Proceedings of the Fifth Symposium on Improving Building Systems in Hot and Humid Climates, Houston, TX.

Domanski, P.A., Yashar, D.A., 2010. EVAP-COND Version 3-Simulation Models for Finned Tube Heat Exchangers with Circuitry Optimization. National Institute of 
Standards and Technology, Gaithersburg, MD.

http://www.nist.gov/el/building_environment/evapcond_software.cfm

Domanski, P.A., Yashar, D. A., Lee, S., Wojtusiak, J., 2011. Practical Aspects of Applying Evolutionary Algorithms for Optimizing Refrigerant Circuitry in Heat Exchangers. Proceedings of the $23^{\text {rd }}$ IIR International Congress of Refrigeration. Prague, Czech Republic.

Fagan, T. J., 1980. The effects of airflow maldistributions on air-to-refrigerant heat exchanger performance. ASHRAE Transactions 86(2): 699-715.

Liu, J., W.J. Wei, G.L. Ding, C.L. Zhang, M. Fukaya, K.J. Wang, T. Inagaki, 2004. A general steady state mathematical model for fin-and-tube heat exchanger based on graph theory, Int. J. Refrig. 27(8): 965-973.

Kaern, M.R., Brix, W., Elmegaard, B., Larsen, L.F.S, 2011. Performance of residential air-conditioning systems with flow maldistribution in fin-and-tube evaporators, Int. J. Refrig. 34: 696-703.

Kaern, M.R., Brix, W., Elmegaard, B., Larsen, L.F.S, 2011. Compensation of flow maldistribution in fin-and-tube evaporators for residential air-conditioning, Int. J. Refrig. 34: $1230-1237$.

Payne, W. V., and Domanski, P. A., 2003. Potential Benefits of Smart Refrigerant Distributors (ARTI-21CR/605-200-50-01; 196 p.)

Wu, Z., Ding, G., Wang, K., Fukaya, M., 2008a. Application of a genetic algorithm to optimize the refrigerant circuit of fin-and-tube heat exchangers for maximum heat transfer or shortest tube Int. J. Thermal Sciences 47(8):985-997.

Wu, Z., Ding, G., Wang, K., Fukaya, M., 2008b. Knowledge-based evolution method for optimizing refrigerant circuitry of fin-and-tube heat exchangers HVAC\&R Research $14(3), 435-451$.

Yashar, D.A., Domanski, P.A., Cho H.H., 2014. An Experimental and Computational Study of Approach Air Distribution for Slanted and A-Shaped Finned-Tube Heat Exchangers. HVAC\&R Research 20, 498-507.

Yashar, D.A., Wojtusiak, J., Kaufman, K., and Domanski, P.A., 2012. A Dual Mode 
Evolutionary Algorithm for Designing Optimized Refrigerant Circuitries for Finned-Tube Heat Exchangers HVAC\&R Research 18(5), SPECIAL ISSUE: Optimization in HVAC\&R, 834-844.

Yashar, D.A., Domanski, P.A., and Cho H.H., 2011. An Experimental and Computational Study of Approach Air Distribution for a Finned-Tube Heat Exchanger. HVAC\&R Research 17(1), 76-85.

Yashar, D.A., and Cho, H.H., 2007. Air-Side Velocity Distribution in Finned-Tube Heat Exchangers. NIST Internal Report 7474, U.S. Department of Commerce, National Institute of Standards and Technology, Gaithersburg, MD.

Yashar, D.A., and Lee, S., 2013. Improving the Performance of a Roof Top AirConditioning Unit by Refrigerant Circuitry Optimization. NIST Technical Note 1806, U.S. Department of Commerce, National Institute of Standards and Technology, Gaithersburg, MD. 